\title{
Determination of the content of promoters in magnetite and wustite phases in the fused iron catalyst
}

\author{
Zofia Lendzion-Bieluńn ${ }^{1}$, Roman Jędrzejewski ${ }^{2}$ \\ 1 West Pomeranian University of Technology, Szczecin, Institute of Inorganic Chemical Technology and Environmental \\ Engineering, 70-322 Szczecin, Pułaskiego 10, Poland \\ ${ }^{1}$ West Pomeranian University of Technology, Szczecin, Institute of Materials Science and Engineering, 70-322 Szczecin, \\ Putaskiego 10, Poland \\ "Corresponding author: zosi@zut.edu.pl
}

\begin{abstract}
Taking advantage of differences in etching rates of crystallographic phases, forming an oxidized form of the fused iron catalyst, a content of promoters in main phases, magnetite and wustite, was determined. A calcium oxide content in magnetite and wustite was $0.54 \mathrm{wt} \%$ and $3.59 \mathrm{wt} \%$, respectively. Aluminum oxide was found in the magnetite phase, and its content was $4.5 \mathrm{wt} \%$. The third promoter, potassium oxide, was almost completely located outside these phases. XRD and ICP-OES instrumental methods were used in the investigations.
\end{abstract}

Keywords: iron catalyst, promoters, ammonia synthesis, selective etching.

\section{INTRODUCTION}

A fused iron catalyst for the ammonia synthesis is formed by fusing of iron oxides with promoters such as calcium, aluminium, and potassium oxides, which are the most frequently use. Magnetite crystallites, with a low content of calcium and aluminium oxides, are being formed in the first stage of the lava crystallization process. As far as the process is advancing, the content of the promoters built-in into the magnetite structure is increasing. Wustite crystallites $\left(\mathrm{Fe}_{1-\mathrm{x}} \mathrm{O}\right)$, rich in calcium oxide and calcium ferrite, are being formed in the next stages of the crystallization process. A glass phase, which contains potassium and silicon oxides, and also a little amount of aluminium, is being formed in the last stage. Distribution of the promoters in particular phases of the oxidized form of the fused iron catalyst depends on conditions of the lava crystallization process ${ }^{1}$.

For the industrial iron catalyst, it was found that aluminium and calcium are built-in into the magnetite structure in $90 \%$ and $36 \%$ of the total amount, respectively ${ }^{2}$. Calcium content in wustite does not exceed 3\% of the whole content. The greatest amount of introduced calcium occurs in intergranular spaces as calcium ferrites, and as well as in the glass phase. The glass phase contains the whole potassium. Distribution of the promoters in the fused iron catalyst depends on $\mathrm{R}$ factor value, which is the molar ratio of $\mathrm{Fe}^{2+}$ and $\mathrm{Fe}^{3+}$ measured for the catalyst ${ }^{3}$. Distribution of the structural promoters, in the oxidized form of the catalyst, influences strongly on the reduced form of the catalyst that is being yielded in the reduction process. The action of the structural promoters is based on their solubility in iron oxides of the oxidized form of the catalyst. The presence of the structural promoters creates favourable conditions for forming the fine-crystalline structure when the catalyst is being reduced. Aluminium oxide, present in the magnetite phase, occurs on the iron crystallites surface as thin layers ${ }^{4}$, making the iron catalyst structure much more stable under ammonia synthesis conditions by preventing the growth of crystallites ${ }^{5}$. Knowledge of the quantitative distribution of the promoters in the catalyst may enable to verify whether the prepared precursor of the catalyst fulfils criteria of the good catalyst.

The electron microscopy in combination with X-ray microanalysis is the most frequently used techniques in the investigations of the elements distribution in catalytic systems. These methods require very sophisticated apparatus and highly qualified staff. It may be difficult to fulfil these conditions in the industrial reality.

The quick determination of particular phases content and their chemical composition in the oxidized form of the catalyst became possible by the simply selective etching method.

The aim of that work was to determine a chemical composition of the main crystallographic phases, magnetite and wustite, in the oxidized form of the fused iron catalyst for the ammonia synthesis by using the mentioned above selective etching method combined with XRD analysis.

\section{MATERIALS AND METHODS}

A fused iron catalyst was prepared by melting magnetite together with promoters oxides such as $\mathrm{CaO}, \mathrm{Al}_{2} \mathrm{O}_{3}$, and $\mathrm{K}_{2} \mathrm{O}$ at the temperature of $1600^{\circ} \mathrm{C}$. The melting process was carried out in the laboratory equipment consisting of an energy supplier (allowing an abrupt change of voltage), a melting tank, and steel water-cooled electrodes. Functioning of the apparatus is based on the electric current conductivity by molten salts and oxides. A detailed description of the apparatus was given in the prior paper $^{6}$. After the melting process, a catalyst lava was tapped into a cooling tank, to crystalize and cool. The prepared catalyst was comminuted.

Chemical composition of the catalyst was determined by ICP-OES method using Perkin Elmer Optima 5300 DV spectrometer. For that purpose, $0.1 \mathrm{~g}$ of the catalyst was dissolved in hydrochloric acid (Suprapur). Dissolving process was carried out using Berghof type Speedw ve microwave oven, in Teflon vessel.

Phase composition of the catalyst was determined by XRD method with Philips X'Pert PRO apparatus. $\mathrm{CuK}_{\alpha}$ radiation was used. For quantitative and qualitative 
analysis by Rietveld's method, Panalytical X'Pert High Score Plus software and ICDD data base were used.

The selective etching method was used to determine the chemical composition of the catalyst phases. For that purpose, 5 samples of the ground catalyst, in the range from 0.1 to $0.2 \mathrm{~mm}$ and mass of $2 \mathrm{~g}$, were placed in flat bottomed flasks, and $100 \mathrm{~cm}^{3}$ of $5 \mathrm{~N}$ hydrochloric acid was added to each one. Different contact times, $0.5 \mathrm{~h}$, $1 \mathrm{~h}, 1.5 \mathrm{~h}, 3 \mathrm{~h}$, and $6.5 \mathrm{~h}$ were used for the reaction. Then catalyst samples were separated by filtration on filter papers. The prepared solution was analysed for iron, calcium, aluminium, and potassium contents by ICP-OES method. XRD analyses were carried out to determine the etching residue content. For the selective etching method, the assumption of constant chemical composition of each examined phase had been made.

\section{RESULTS AND DISCUSSION}

XRD analysis of the oxidized form of the catalyst showed the presence of three crystallographic phases, Fig. 1. Quantitative composition of the investigated catalyst was carried out by Ritveld's method. It was found that the main phase was $\mathrm{Fe}_{3} \mathrm{O}_{4}$, and its content was $75.3 \mathrm{wt} \%$. Phases $\mathrm{FeO}$ and $\mathrm{CaFe}_{3} \mathrm{O}_{5}$ were found with contents $9.2 \mathrm{wt} \%$ and $15.5 \mathrm{wt} \%$, respectively. It was known from previous investigations that the oxidized form of the iron catalyst contains also amorphic phase called glass phase ${ }^{1}$. Chemical composition of the catalyst was determined by the ICP-OES method. Contents of elements in the catalyst were: iron $66.5 \mathrm{wt} \%$, calcium $1.85 \mathrm{wt} \%$, aluminium $1.75 \mathrm{wt} \%$ and potassium $0.56 \mathrm{wt} \%$.

The X-ray patterns, at the angle range $2 \Theta$ from $29^{\circ}$ do $45^{\circ}$, for catalyst residues after the etching process and different contact times with hydrochloric acid solution, are shown in Fig. 1. There are the most intensive peaks belonging to examined crystallographic phases at the selected range. The decrease in $\mathrm{CaFe}_{3} \mathrm{O}_{5}$ peaks intensity was observed in the first stage, Fig. 1B. In the next one, Fig. 1C, there were no peaks belonging to that phase and also decreasing of $\mathrm{FeO}$ peaks intensity was observed. There were only magnetite phase peaks in the last X-ray pattern.

Changes in crystallographic phase contents of the etching residues and concentrations of promoters in the solution, calcium, aluminium, and potassium, after the etching process as a function of the iron etching degree, $\mathrm{E}_{\mathrm{Fe}}$, are shown in Fig. 2.

$\mathrm{E}_{\mathrm{Fe}}=\frac{\mathrm{m}}{\mathrm{m}_{\mathrm{o}}} 100 \%$

Where: $\mathrm{m}$ is mass of iron in the solution, $\mathrm{m}_{\mathrm{o}}$ is mass of iron in the initial sample.

After the contact time of $0.5 \mathrm{~h}$, the catalyst with the acid solution, the iron etching degree was $22 \mathrm{wt} \%$. $\mathrm{Fe}_{3} \mathrm{O}_{4}$ phase content in the residue after etching process, determined by XRD method, increased to $94.5 \mathrm{wt} \%$, while contents of other crystallographic phases, $\mathrm{Fe}_{1-\mathrm{x}} \mathrm{O}_{\mathrm{x}}$ and $\mathrm{CaFe}_{3} \mathrm{O}_{5}$, were reduced to $3.8 \mathrm{wt} \%$ and $1.8 \mathrm{wt} \%$, respectively. Extension of the contact time to $1.5 \mathrm{~h}$ brought about that $\mathrm{CaFe}_{3} \mathrm{O}_{5}$ was dissolved completely, and iron etching degree was $37.5 \mathrm{wt} \%$.

It was found by XRD analysis that for the iron etching degree of $45.1 \mathrm{wt} \%, \mathrm{Fe}_{3} \mathrm{O}_{4}$ phase only was present. On the basis of the chemical analysis of calcium and potassium concentrations, in the solution after the etching process, at the last measuring point (3), and total catalyst chemical compositions, contents of calcium and potassium in the magnetite phase were determined, Table $1 . \mathrm{CaO}$ content, in magnetite phase, was $0.54 \mathrm{wt} \%$, and $\mathrm{Al}_{2} \mathrm{O}_{3}$ content was $4.5 \mathrm{wt} \%$.

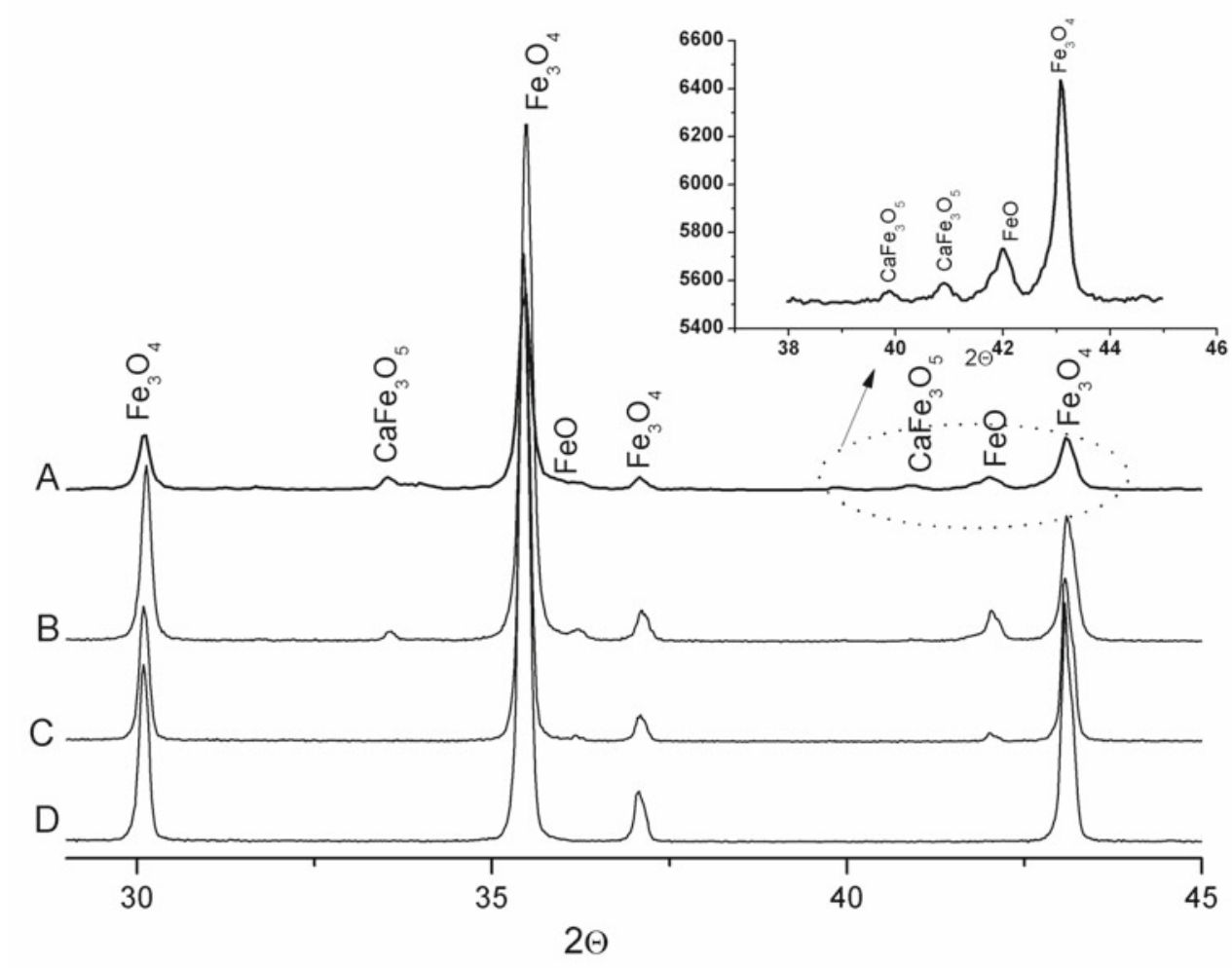

Figure 1. X-ray patterns of the catalysts after selective etching. A is for the contact time $\mathrm{t}=0 \mathrm{~h}$, $\mathrm{B}$ is for the contact time $\mathrm{t}=0.5 \mathrm{~h}, \mathrm{C}$ is for the contact time $\mathrm{t}=2 \mathrm{~h}, \mathrm{D}$ is for the contact time $\mathrm{t}=6.5 \mathrm{~h}$ 


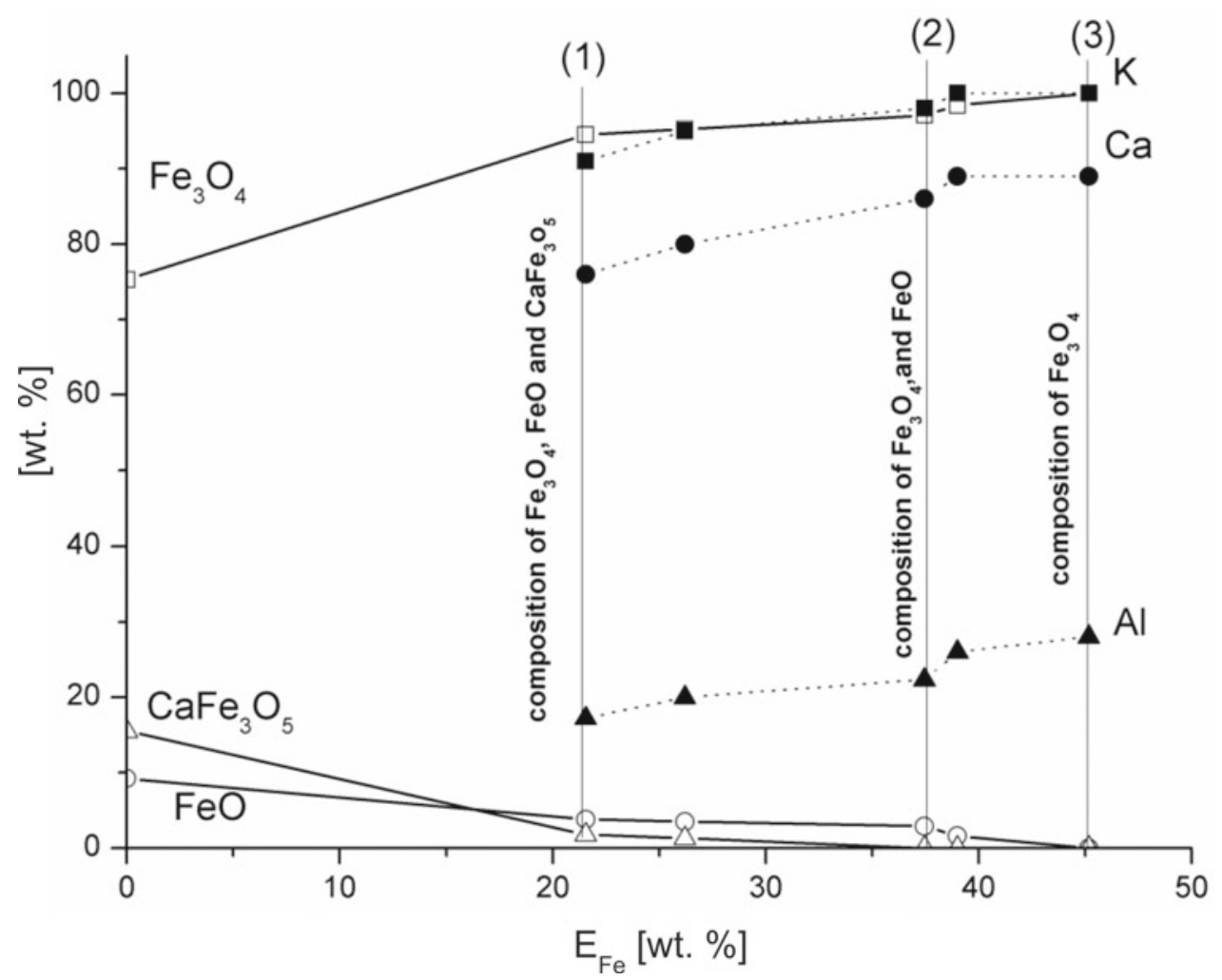

Figure 2. Changes of the crystallographic phases and promoters contents versus the iron etching degree

Table 1. Chemical composition of the crystallographic phases in the investigated catalyst

\begin{tabular}{|l|c|c|}
\hline \multirow{2}{*}{ Crystallographic phase } & \multicolumn{2}{|c|}{ Content [wt\%] } \\
\cline { 2 - 3 } & $\mathrm{CaO}$ & $\mathrm{Al}_{2} \mathrm{O}_{3}$ \\
\hline $\mathrm{Fe}_{3} \mathrm{O}_{4}$ & 0.54 & 4.5 \\
\hline $\mathrm{FeO}$ & 3.59 & 0.0 \\
\hline
\end{tabular}

Promoters contents in wustite phase were calculated on the basis of the results at point 2, in Fig. 2. Knowing magnetite and wustite mass ratio, XRD analysis, and iron quantity at that point, quantities of magnetite and wustite phases were calculated. Working on the assumption that chemical compositions of the phases are constant and considering contents of calcium and aluminium oxides in the magnetite phase, calculated from point 3 , contents of $\mathrm{CaO}$ and $\mathrm{Al}_{2} \mathrm{O}_{3}$ in wustite phase were calculated.

There was the highest calcium oxide content of 3.59 wt $\%$ in wustite phase $\mathrm{Fe}_{1-\mathrm{x}} \mathrm{O}_{\mathrm{x}}$. Aluminium was built-in into magnetite phase, and its content, as aluminium oxide, was $4.5 \mathrm{wt} \%$. The whole of potassium oxide was located in the intergranular spaces, outside the wustite and magnetite phases.

\section{CONCLUSIONS}

The iron fused catalyst doped by oxides of calcium, aluminium, and potassium was prepared by the melting process. Total chemical composition of the prepared catalyst, determined by ICP-OES method, corresponds to the industrial iron catalyst ${ }^{1}$. Combination of the selective etching method and powder XRD analysis enabled to determine promoter contents in wustite and magnetite phases in the iron fused catalyst. Calcium oxide content is slightly lower in magnetite and wustite phases, and aluminium oxide content is slightly higher in comparison with the industrial iron catalyst. In previous investigations of the industrial iron catalyst calcium oxide and aluminium oxide contents were $0.63 \%$ and $4.9 \%$, respectively, and aluminium oxide content in magnetite phase was $3.3 \%{ }^{1}$.

\section{LITERATURE CITED}

1. Lendzion-Bielun, Z., Jedrzejewski, R. \& Arabczyk, W. (2011). Heterogenity of ingot of the fused iron catalyst for ammonia synthesis. Appl. Catal. A: General, 400, 48-53. DOI:_10.1016/j.apcata.2011.04.010.

2. Lendzion-Bielun, Z. \& Arabczyk, W. (2001). Method for determination of the chemical composition of phases of the iron catalyst precursor for ammonia synthesis. Appl. Catal. A: General, 207, 37-41. DOI: 10.1016/S0926860X(00)00614-1.

3. Lendzion-Bielun, Z., Arabczyk, W. \& Figurski, M.,(2002). The effect of the iron oxidation degree on distribution of promotors in the fused catalyst precursors and their activity in the ammonia synthesis reaction. Appl. Catal. A: General, 227, 255-263. DOI: 10.1016/ S0926-860X(01)00938-3.

4. Pennock, G.M., Flower, H.M. \& Andrew, S.P.S. (1987). The mechanism of formation of ammonia synthesis catalyst. J. Catal.,103 (1), 1-19.

5. Somorjai, G.A. \& Materer, N. (1994). Surface structures in ammonia synthesis. Topics in Catal.,1 (3-4), 215-231. DOI: 10.1007/BF01492277.

6. Arabczyk, W., Ziebro, J., Kałucki, K., Świerkowski, R. \& Jakrzewska, M. Laboratory scale plant for continuous fusing of iron catalysts, Chemik, 1 (1996), 3-7.(In Polish). 